\title{
Argumentation in Theory and Practice: Gap or Equilibrium?
}

\section{TONE KVERNBEKK}

University of Oslo

Department of Educational Research

PO Box 1092 Blindern

0317 Oslo

Norway

tone.kvernbekk@ped.uio.no

\begin{abstract}
I address the problem of the relation between theory and practice, with a special view to the relation of argumentation theory to argumentative practice. It is common, in argumentation and in various professions, to diagnose a 'gap' between theory and practice, often followed by arguments that gaps are problematic and should be overcome. Closing the gap generally amounts to some sort of equilibrium view, where theory and practice are balanced, in line with each other. With some qualifications, I argue that a version of a gap is sound, as it leaves theory with a critical, independent role in relation to practicewhich an equilibrium view does not.
\end{abstract}

\section{Introduction}

All professions have what is generally termed a theory-practice

problem. But what does this problem consist in? Not unsurpris-

(C) Tone Kvernbekk. Informal Logic, Vol. 32, No. 3 (2012), pp. 288-305.
Résumé: Cet article traite du problème de la relation entre la théorie et la pratique, avec une attention particulière à la relation de la théorie de l'argumentation à la pratique argumentative. Il n'est pas rare, dans professions, de diagnostiquer un «écart» entre la théorie et la pratique. Le diagnostic est souvent suivi par des arguments que les écarts sont problématiques et qu'ils doivent être réduits. Combler l'écart en général revient à une sorte de vue d'équilibre, où la théorie et la pratique sont équilibrées, en conformité avec l'un et l'autre. Je soutiendrai avec certaines réserves qu'une version d'un écart est saine, car elle laisse la théorie avec un rôle critique et indépendant par rapport à la pratiquequelque chose qui un point de vue d'équilibre laisse de côté. l'argumentation et dans diverses

Keywords: Balance, bridge, Dewey, equilibrium, gap, Goodman, Johnson, practice, theory, Toulmin.$$
\text { pp. } 288
$$ 
ingly, answers to that question differ widely. In education, for example, we find it treated by some as a "what comes first" issue. Theoreticians and researchers might complain that practitioners do not use available scientific, research-based knowledge in their work, but rather rely on common sense and old bags of tricks. Practitioners frequently complain that research-based, theoretical knowledge is too abstract and general to be of any use in practical contexts; often with the added complaint that the theory produced by theoreticians simply is not relevant, it does not address the issues that practitioners are interested in. Sometimes it is claimed that practice is self-sufficient, it does not need theory. And occasionally it is claimed that theory pursuit is (or should be) an end in itself, free of practical concerns.

Even a discipline such as argumentation has a theorypractice problem. In this paper I shall discuss a small selection of aspects of the theory-practice problem, and my discussion is meta-theoretical. That is to say, I shall treat "theory" and "practice" as large, abstract entities and discuss their relationship from a "bird's-eye" perspective; I shall not look at how the relationship might play out between particular theories and practices. First, I shall look into how the problem has been diagnosed; namely as consisting in a gap between theory and practice. Second, I shall focus specifically on the concept of a theory and draw a distinction between "weak" and "strong" theory in order to get a better grip on the different functions that theories can perform in relation to practice. Third, I inquire into a way of thinking that treats theory and practice in terms of an "equilibrium," that is, where there is no gap. Finally, I shall argue that some version of a gap is a sound way of understanding the relationship, if theory is to keep its critical potential and preserve a dignity in its own right.

\section{Gaps: Theory and practice being out of sync}

In his seminal work The Uses of Argument (1958/2003) Stephen Toulmin diagnoses a gap between logical theory and critical practice. The gap seems to come down to a mismatch between theory and practice. The problem, in Toulmin's view, stems from the ambition to cast logic in a geometrical or mathematical form, and the resulting insistence that all arguments can be treated as analytical arguments. This theory does not accommodate actual practice. Much of his book, as I read it, is devoted to showing that while formal logic nicely fits analytical arguments, it does not fit substantial arguments and judgments. Attempts at moulding all types of arguments in an analytical cast will do 


\section{Tone Kvernbekk}

violence to the non-analytical types of argument. Substantial arguments need fresh categories, Toulmin argues. The traditional, geometrical way of looking at arguments, as premises and inference to a necessary conclusion, is inadequate and needs to be revised. Toward the end of his book he concludes that a "radical re-ordering of logical theory is needed in order to bring it more nearly into line with critical practice, and our justification will come only if the distinctions and objections insisted on here will bring such a re-ordering nearer" (1958/2003: 234). His own work can be viewed as an attempt at providing precisely that, i.e., a new, different form of argument structure that would fit what we actually do when we produce arguments or assess judgments.

No doubt a more detailed analysis of various aspects of Toulmin's argumentation theory would be both pertinent and interesting. I am, however, in this paper interested in the big theory/practice picture, so I will at this point content myself with a brief, preliminary observation. We have met here an understanding of 'gap' which means, it seems to me, that theory and practice do not match - an understanding of 'gap' I suspect is widespread in many professions. What we think, say or find in textbooks is not what we do.

Ralph Johnson, in his book Manifest Rationality (2000), makes much the same diagnosis as Toulmin: there is a gap between theory and practice in the field of argumentation. Johnson's understanding of 'gap' also seems to be much the same as Toulmin's; that there is a mismatch between theory and practice. There is (still) a difference between what we do and what we think. In commenting on Toulmin's suggestion that a radical reordering of theory is needed, Johnson remarks that a possible remedy might also be to bring practice in line with theory. However, in the end his own proposed remedy is very similar to Toulmin's: "[...] the gap can only be bridged by significant alterations to the theory" (2000: 358).

Here we could naturally ask just how radical a re-ordering or how significant an alteration of theory we should opt for. In his Introduction Toulmin defines his own project in a rather radical fashion: "In tackling our main problems about the assessment of arguments, it will be worthwhile clearing our minds of ideas derived from existing logical theory and seeing by direct introspection what are the categories in terms of which we actually express our assessment, and what precisely they mean to us." But as Johnson (2005: 6) observes, Toulmin in fact retained many elements of the mathematical argument model he rejected and wanted to replace, such as "logical form," "logical possibility" and "validity." New ways of thinking generally owe 
some debt to existing theory. The re-ordering cannot be all that radical, Johnson argues, because we cannot wipe the slate completely clean, banish all existing terms and invent brand new categories. But more importantly, for my purposes here: the gap is a problem, and the way to remedy it is to change the theory.

To speak about a "gap" is, of course, to speak metaphorically. I have suggested that Toulmin and Johnson both conceive of it as mismatch. One can imagine here that such mismatches come in degrees, and that big mismatches are more serious and difficult to remedy than smaller ones. 'Gap' may signal a complete separation of theory from practice, perhaps this is what is meant when Toulmin occasionally also uses the term 'gulf.' When understood in this way, 'gap' immediately invokes another metaphor; that of a "bridge." If there is a gap between two (or more) things that we think should hang together, we naturally want to remedy the gap and this is generally thought of as building a bridge across it. What does this tell us about the conceptions of theory and practice that are at play? At the outset, the metaphors of 'gap' and 'bridge' may make theory and practice seem like two completely separated entities. Do they indicate that theory is theoretical and that practice is theory-free? For the record, I do not attribute such a "complete separation" view to Toulmin and Johnson, despite their calls for radical reorderings of and significant alterations to the theory.

Other ways of describing the gap could be to describe the theory/practice relationship in terms of "no fit," "distance" or "difference;" the latter seemingly not so serious. One may even describe the gap as only "apparent," if one thinks it is based on a misunderstanding. But why should we conceive of it as a problem, as something we should remedy? If you are a theoretician, pursuing theory for its own sake, you probably would not see a theory/practice gap as a problem at all. The gap becomes a problem, I suggest, if you think that theory and practice should be in a given relationship. They should somehow hang together, do some kind of job for each other, perform certain functions for each other. In Toulmin and Johnson's big picture of theory/practice, practice should guide theory so that theory that is not descriptive of practice would need to be revised and brought in line with practice. I shall come back to the question of what we stand to gain by such a move.

\section{The concept of a theory}

At this point there emerges a need to look into the question of what a theory is (for a discussion of the concept of practice in 


\section{Tone Kvernbekk}

argumentation, see Kvernbekk 2008). I do not propose a fullfledged discussion of the concept of a theory here, but I do wish to make a distinction concerning the use of the term. This distinction is by no means perfect, but it does have a bearing on the theory-practice problem and might serve to illuminate further Toulmin and Johnson's views. It is the distinction between strong" and "weak" notions of the theoretical. A strong use of the terms 'theory' or 'theoretical' would be to regard it as a well-articulated theory dealing with a carefully delineated aspect of the world; a theory that in Sylvain Bromberger's classical formulation can be "accepted, rejected, believed, remembered, stated, granted, confirmed, refuted, have authors" (1963: 83). Incidentally, the strong notion is what Robert Pinto, in reflective hindsight, found that his theoretical efforts have not satisfied or lived up to (Pinto 2001). Pinto makes the judgment that while his ideas were both valid and important, they did not "add up to the elaboration of a theory" (p. 128); rather, they were fragmented and incomplete.

A weaker sense of 'theory' (or theoretical) is what we find in claims, views and beliefs that clearly go beyond the observational, both concerning terms and assumptions, but which may fall short of explicit articulation, be only partly articulated, and/or be too "loose" to qualify as a theory. Most claims about everyday events and happenings are of this kind. Theory in the weak sense is of vital importance in the theory-practice debate. Philosopher of education Wilfred Carr (1995), in his claims that educational practice is fundamentally theory-laden, relies on a weak sense of theory. This is analogous to Norwood Russell Hanson's famous thesis that all observation is theory-laden (Hanson 1958). There is no such thing as theory-free observation; all observation is shaped by the purposes and prior knowledge of the observer. Observation may be seen as a type of practice, and it is not unreasonable to construe the theorypractice relationship along the lines of the theory-observation relationship. Educational practice, Carr says, is full of more or less implicit assumptions and beliefs concerning unobservable entities and connections of various kinds; that is, theory in the weak sense.

Does it make sense to say that there is a gap between theory and practice if Carr is right and practice is infused with (this kind of) theory? It would seem that if practice is always theoryladen, there is no gap between theory and practice in the strongest sense of 'gap' delineated above (theory and practice as completely separated entities because practice is considered theoryfree). The theory in a theory-laden practice will always fit the practice, since it is the way the practice is understood and de- 
described. Can we still then speak of a gap? If so, what could it mean? There are several possibilities.

If we diagnose a gap with the strong/weak distinction in mind, the mismatch may not be so much between theory and practice as between strong and weak theory. We may become aware of the discrepancy and wish to overcome it by changing the strong theory. Alternatively, those who diagnose a gap may rather want to argue that the theory with which practice is laden is inadequate. If that is the case, then there is a gap in the sense that the theory which informs practice is not the theory we want to inform practice. We might wish to transform or replace the old weak theory, old ways of seeing and understanding, with new, allegedly better or more adequate theory.

One more point needs to be made concerning the views of Toulmin and Johnson. Their theories are both theories in the strong sense, well-articulated accounts of some delineated aspect of the world (the domain of argumentation). Practice can, I presume, be laden with theory both in the strong and the weak sense. Some parts of practice may be informed by carefully argued theories of argument(ation). But there will always also be theory in the weak sense: preconceptions, prior knowledge, misunderstandings, prejudices and unarticulated assumptions that shape what we see, perceive, think and do. It is my hypothesis that theory in the strong sense cannot hope to replace all theory in the weak sense in a theory-laden practice. Nor do I see why it should; an issue I shall return to.

First let me look into the question of altering or reordering the theory to make it fit practice. Why should we change the theory and not the practice? Leaving aside the fact that changing theory is quicker and easier than changing practice, is there some tacit assumption here that practice is unproblematic and thus can be taken for granted, so that if the theory does not match it is obvious that the theory needs revision? Toulmin, as I read him, does not address that particular question, but it is obvious that he thinks that logical theory (argumentation theory), such as it was at the time he wrote the book, by no means accommodates critical practice and the types of arguments that people actually employ. The strong theory does violence to the practice. Whatever weak theory might inform this practice, he does not discuss.

Let me briefly revisit the interpretation of 'gap' touched upon above; that the theory which informs practice is not the theory we want to inform practice. Such theory is likely to be weak and largely implicit. If we find this theory inadequate, is that because we also find the practice (somewhat) inadequate? If so, a strong theory that does not match practice would rather 


\section{Tone Kvernbekk}

suggest that practice should be changed, not the theory. I would like here to invoke Roger Wertheimer's distinction between what he calls systems of actuality and systems of ideality (Wertheimer 1972), which has a bearing on the question of whether the theory or the practice should be changed if the job is to bring them into line and thus bridge the gap.

By system Wertheimer means a "... more or less well organized and integrated system of laws ... concerning some more or less well-defined set of properties of some more or less welldefined set of objects" (1972: 88). A scientific theory (theory in the strong sense) is a paradigm case of a system of actuality; a moral code is a paradigm case of a system of ideality. Both types, he says, entertains the same form of laws, the difference lies in what is done with the law. A law is a generalization of the form " $(\mathrm{x})(\mathrm{Fx} \rightarrow \mathrm{Vx})$," which sustains counterfactual conditionals, but this definition itself is of no importance to my concerns here. Within systems of ideality, writers do not intend to describe regularities in actual behaviour and what they say is not falsified by deviations from this regularity (or practice). Rather, a system of ideality describes what people do when they act in conformity with this system. If people do not act accordingly, we do not judge the system of ideality and its laws to be wrong; instead we judge the actors to be wrong in doing what they do. In such a system, therefore, the law is used as a basis for assessing both instances and counter-instances to the law. This would apply equally to rules or norms for argumentation: if we fail to live up to them, we are to be blamed, not the rules. Rules and norms may be criticized for many reasons but hardly on grounds that we fail to live up to them. The matter may be a different one if the rules are formulated in such a way that we cannot live up to them; then they may be criticized as too strict or unrealistic.

In systems of actuality, on the other hand, the law is judged to be wrong if cases of deviation are discovered. In other words, the instances and counter-instances are used as grounds for assessing the law. Wertheimer's characterization of systems of ideality and actuality may be crude and unsatisfactory, but it serves to highlight the following problem: is logical (argumentation) theory a system of ideality or a system of actuality? The answer to this question, it seems to me, has an interesting bearing on how we understand the relation of argumentation theory to argumentative practice, giving it a normative dimension in the manner Wertheimer does. Is it theory that exerts normative pressure on practice, so that if practice fails to live up to theory we judge practice deficient and in need of revision? Or is it practice that guides theory, so that if theory is mismatched to existing 
practice we judge theory deficient and in need of revision? As we have seen, Toulmin and Johnson opt for the latter, thus implying that argumentation theory is more like a system of actuality.

\section{Equilibrium: Theory and practice being in line}

To reiterate, Toulmin calls for a radical re-ordering of theory. All theory, he says, should be tested "against our actual practice of argument-assessment, rather than against a philosopher's ideal" (1958/2003: 10). Then we shall be able to build up a picture of logic very different from the traditional one. Johnson (2000) concurs with this view; in 2005 he suggests that the relationship of theory and practice better be viewed as reciprocal, in a Deweyan fashion.

But why should theory and practice be brought into line? What do we stand to gain by such a move? And what does it mean, exactly, for theory and practice to be in line? One thing that it does seem to mean for Toulmin is that theory then would be descriptively correct of practice. Theory here refers to explicit, articulated logical (argumentation) theory. It is this theory that must be changed to fit practice. In the weak sense of theory, as found in the notion of theory-laden practice, theory and practice already hang closely together, quite possibly in a reciprocal fashion. But should theory in the strong sense do the same?

Before we delve into these questions, it is necessary to address the issue of the function of theories - and here I speak of theory in the strong sense. What job(s) do we want our theory to do in relation to practice? Generally, theories are thought to provide descriptions, explanations and predictions of the phenomena within their scope. We might add that they can also be used as instruments to modify the world, often expressed as theory for practice. Other suggestions might be to guide, prescribe, illuminate, ground, justify.

Does the ascribed function have a bearing on how one envisions the relationship in terms of gaps or of being in line; and, if so, how? It is not entirely clear to me what Toulmin and Johnson take the function of theory to be besides what I have already hinted at; namely that it should provide correct descriptions of practice. Robert Pinto (2001) seems to hold that ideally the job of a theory is to ground critical practice, but he doubts that it is at all possible to construct such a theory. He grants that theory might illuminate practice, though. Johnson (2005), in his discussion of Pinto's views, problematizes Pinto's assumptions 


\section{Tone Kvernbekk}

that a theory would have to be systematic and complete, and that the job of any theory worth the name is to provide a foundation for practice.

\subsection{Deweyan reciprocity}

The Deweyan picture of reciprocity-theory and practice being continually revised in light of each other-naturally seems attractive; a dynamic relationship that allows both parts to develop. Johnson (2005) explicitly suggests this as a remedy for the gap, but thinks that this way is not open to Toulmin because in the last analysis Toulmin tacitly relies on Cartesian ideas. Toulmin begins in practice. As he himself describes his procedure, he starts by characterizing the main concepts used in practice. That done, we can look at what sort of theory we might build up that could have the required kind of application. We should, he urges, clear our heads of existing logical theory so we can see by direct introspection what categories we actually use.

Pinto clearly also begins in practice. His overall view of the argumentation enterprise is that "our judgments about arguments and inference are guided by a tradition of critical practice rather than by an over-arching theory" (2001: 129). In my terminology, this might amount to judgments/practice being guided by the theory in the weak sense which informs and shapes practice. Michael Gilbert (2007) also seems to begin in practice in his discussion of how to build normative controls on everyday argument. It is a kind of natural normativity, he argues, that grows organically from goals, context and ethos of situations in which argumentation happens. The situation must be examined to understand the rules involved. If I understand him correctly, Gilbert thinks that natural normativity grows out of practice. This is an echo of Dewey, who explains the nature of logical ideas and principles as follows:

Any habit is a way or a manner of action, not a particular act or deed. When it is formulated, it becomes, as far as it is accepted, a rule, or more generally, a principle or "law" of action. It can hardly be denied that there are habits of inference and that they may be formulated as rules or principles (Dewey 1938/1991: 21).

Hence, in Dewey's view habits of inference might begin by being simply habits, but develop into rules. Some rules, Dewey says, may be necessary to every successful inferential inquiry. "Successful" means the inquiry in the long run yields results that are either confirmed in further inquiry, or corrected by use of the same procedures. That is to say, the reciprocity of theory and 
practice is close-knit. In passing, it is worth noting that while Toulmin seemingly goes a long way in accepting such a view, e.g., in his insistence that all logical ideas should be tested against practice, I agree with Johnson that he does resist going all the way. We must, Toulmin says, distinguish between pathological and normal habits and practices. That is, logical ideas should not be tested against any critical practice. Also, the logician "is a student of proper inferring-habits and of rational canons of inference" (4, my emphasis). This is a particularly interesting viewpoint, since it suggests that he (also) views logic as a system of ideality in Wertheimer's understanding of the term, whereas many of his other viewpoints suggest he sees it more as a system of actuality.

Ralph Johnson (2005) also opts for a reciprocal Deweyan way of understanding the relationship between theory and practice. Standards and rules arise out of practice and feed back into practice in a way that modifies practice, making it more effective and/or adequate. But what kind of reciprocity is hiding here? It can be argued, it seems to me, that Dewey views theory as subordinate to practice. In The Quest for Certainty $(1929 / 1988)$ he states that the value of ideas "is determined by the outcome of these operations. They [the values] are sound if the operations they direct give us the results which are required" (110). Hence, all ideas must be tested against practice; it is their function to contribute to change and development: “... all ideas are worthless except as they pass into actions which re-arrange and reconstruct in some way, be it little or large, the world in which we live" (111). As Israel Scheffler (1973: 151) comments in his explication of Dewey's position, the function of theory and thought is to reconstruct practice by deliberately solving problems as they occur, more efficiently than stereotypical repetition and random variation could. Theory is widely understood as what we think and practice is widely understood as what we do.

How adequate is the reciprocal view of theory and practice? I shall argue that while much of what Dewey says is acceptable and his views have attracted a number of followers in many domains, there might be a price to pay for adopting his view on theory and practice-and it is theory that pays the price. Dewey's basic way of thinking is holistic. He fervently wants to overcome dualisms, such as theory/practice, means/end and mind/body. In that sense he seems like a good choice for those who wish to bridge the gap between theory and practice. Theory arises from problems encountered in practice, its function is to solve these problems intelligently and thereby transform practice, in an ongoing process. Theory begins and ends in practice. 


\section{Tone Kvernbekk}

Is this what Toulmin is after in a logical theory? If existing theory is completely out of sync with practice it is hardly of any value, Dewey tells us. It is not obvious that a radical re-ordering of such theory would give it the function Dewey suggests for theory, even if it became descriptively true of practice. Correspondence is not of interest, transformation is. This holds generally for Dewey, hence it would also hold for the domains of argumentation and education.

I would like at this point to briefly introduce the views of the German philosopher of education Erich Weniger (1990). In an essay originally published in 1929 he voices views about the theory/practice relationship in education that are highly similar to Dewey's, even though Weniger is not a pragmatist. Weniger has a complex notion of theory. He distinguishes between three different degrees of theory; the first being an implicit, largely unarticulated fundamental ethical attitude of educational responsibility. A theory of the second degree is comprised of the beliefs and knowledge that the practitioner possesses, and which he/she can articulate and employ. But this is not enough. At the point of intersection between theories of first and second degree arises one of the most basic problems of educational theory; the question of the relationship between reality and theory, what is and what should be, etc. A genuine educational theory, Weniger claims, crucially turns on the consistency of first and second degree theories. If a discrepancy exists between the two, the resulting practice will be untrue, not genuine, since there is disagreement between ethical attitudes and espoused views. And here the theory of the third degree enters the picture, to have the relation between theories of first and second degree in practice as its object. Such a theory presupposes an already theory-laden practice, and it is only valid, Weniger says, to the extent that it makes practice more rational, less random.

There can be no doubt that for both Dewey and Weniger theory and practice are very much in line. But is this a good thing? Like Dewey's theory, Weniger's theory never gets out of practice. It proves its worth in practice. Its justification depends on its practical, instrumental merits; to what degree it yields the required results. Israel Scheffler (1973: 149-159), in a lucid discussion of Dewey's views on thought and action, voices several illuminating criticisms. First, he suggests that Dewey, in his endeavour to show that all dualisms (such as theory and practice) really are partial views which belong together in a unified, more inclusive framework, runs the risk of mistaking valid distinctions for divorces, splits, sharp divisions - gaps and gulfs, if we like. Second, his conception of the function of ideas (theory) 
is unduly narrow, Scheffler thinks, if the only function ideas are to have is to transform practice. In fact, Scheffler suggests, ideas are of different kinds and "only certain simple types can be analyzed as instruments for transforming the world" (1973: 154). Third and closely connected to the previous point, Scheffler argues that Dewey overlooks the vital importance and centrality of theoretical considerations in science, e.g., concerning the weighing of evidence.

Dewey, on his part, denies that we can meaningfully distinguish between descriptive and instrumental functions of thought. All thinking originates in problems (this is a generalization of the features of experimental research), and all ideas eventually feed back into action and practice. As a fourth criticism, Scheffler points out that for Dewey even reflection concerns the functioning of knowledge, and again Scheffler finds this unduly narrow. Dewey's view is remarkably like Weniger's, although Weniger addresses educational thinking in particular and does not presume to speak in general terms. The function of the most "theoretical" of theories, Weniger says, is to contribute to practice. But, we may argue, not even educational theories are assessed solely in terms of how they pass into action; they are judged in theoretical terms using time-honored criteria such as clarity, internal consistency and empirical adequacy. A theory that is preoccupied with justifying itself as effective in practice may not have the requisite distance from practice to serve as a critical tool.

Summing up, while some theories within a field or domain, such as argumentation or education, might well be thought of as arising from practice and going back into practice, we should not demand this of all theories (in the strong version of theory). It amounts to imposing an unnecessary restraint on theories. The theories of a given domain may have different functions, and besides, theory as an academic pursuit should be regarded as worthwhile in itself. Problem finding may be just as important as problem solving.

\subsection{Goodmanian equilibrium}

Nelson Goodman (1983) provides a different way of bringing theory and practice into line. The "being in line" in this case is not a question of reciprocity, but of balance or equilibrium. Granted, Goodman specifically talks about justification, but I will apply his views to theory and practice in general. The basic idea is that theory and practice justify each other when brought into equilibrium. As he himself puts it, 


\section{Tone Kvernbekk}

How do we justify a deduction? Plainly, by showing that it conforms to the general rules of deductive inference. An argument that so conforms, is justified or valid, even if its conclusion happens to be false. [...] Yet, of course, the rules themselves must eventually be justified. The validity of a deduction depends not upon conformity to any purely arbitrary rules we may contrive, but upon conformity to valid rules. ... But how is the validity of rules to be determined? [...] Principles of deductive inference are justified by their conformity with accepted deductive practice. Their validity depends upon accordance with the

particular deductive inferences we actually make and sanction (1983: 63).

Goodman then continues, admitting that this looks circular but denying that it is a problem:

This looks flagrantly circular. I have said that deductive inferences are justified by their conformity to valid general rules, and that general rules are justified by their conformity to valid inferences. But the circle is a virtuous one. The point is that rules and particular inferences alike are justified by being brought into agreement with each other. [...] The process of justification is the delicate one of making mutual adjustments between rules and accepted inferences, and in the agreement achieved lies the only justification needed for either (p. 64).

If theory and practice exhibit this kind of balance or equilibrium, they have clearly been brought in line. So can this form of "being in line" be what Toulmin and Johnson are looking for? As Hilary Putnam points out in his foreword to Goodman's book, Dewey would also regard this circle as virtuous (Putnam 1983). One might perhaps say that Goodman pictures the relationship as static, kept in balance, whereas Dewey sees it as continuous transformation. In Toulmin's case, if theory is reordered so that it is brought into line with practice, then they would mutually justify each other. Theory is justified if it conforms to practice, and practice is justified if it conforms to theory. I see nothing in Toulmin's text, however, to suggest that this is what he wants.

It should be remembered here that for Goodman, the problem of justifying rules is tantamount to showing that they are valid. A rule is valid if it accords with established practice, if it accurately codifies that practice. An unjustified, invalid rule fails to describe practice. But this is problematic, Harvey Siegel argues (Siegel 1992). In fact, he claims, codification or practice 
is neither necessary nor sufficient for the justification and validity of inferential rules. Modus ponens, for example, is a rule that is justified and valid, but it fails to codify inferential practice since people often do not reason in accordance with it. Accordance with practice is thus not necessary for the validity of rules. On Goodman's view, the rule is invalid, unjustified. Furthermore, Siegel argues, many people do infer in accordance with the principle of hasty generalization, despite the fact that it is an invalid, unjustified principle. Thus, accordance with practice is not sufficient for the validity and justification of inferential principles. Goodman, for his part, would be forced to say that the principle is valid, since it does codify practice. We could ask here, though, whether we could relax the requirement somewhat; modus ponens may fail to codify all inferential practice, but it surely codifies some. This would add another layer of complexity to the problem, since it would have the result that theory and practice sometimes are balanced and sometimes not. Be that as it may, the basic question, Siegel says, is why we should think that an equilibrium would serve to justify either.

If any two entities are in a balance of the kind Goodman envisions, then it should not matter where one begins to investigate inferential rules and practice and the relationship between them. But just like the Deweyan reciprocity discussed above seemed to have a certain bias in favor of practice, so does the Goodmanian equilibrium. Practice takes precedence. Putnam, in his foreword, makes this very clear:

Few philosophers are less aprioristic than Goodman. What he insists upon, and all that he insists upon in this connection, is that any proposed solution be judged by its ability to systematize what we actually do (1983: xiii).

Goodman, Putnam says, respects formal logic but not when it describes problems in ways that have no pay-offs in practice. As Goodman himself expresses it,

Principles of deductive inference are justified by their conformity with accepted deductive practice. Their validity depends upon accordance with the particular deductive inferences we actually make and sanction. If a rule yields inacceptable inferences, we drop it as invalid (1983: 63-64).

As suggested above, this seems to capture what Michael Gilbert has in mind with his concept of natural normativity. But I think perhaps not quite. One the one hand, Gilbert says that the normative aspect of natural normativity arises from social pres- 


\section{Tone Kvernbekk}

sures, from others, ourselves and from the situation itself. The natural aspect points to natural normativity arising organically from the three core elements of goals, context and ethos. This I have interpreted as suggesting that Gilbert thinks that norms and rules grow out of practice in the Deweyan sense delineated above. But on the other hand Gilbert also says that he is trying to build a foundation for normative controls on everyday argument (154); and the idea of a foundation is not compatible with a Deweyan perspective. Furthermore, he states that rules must be grounded to support and uphold a distinction between acceptable and unacceptable arguments (150). In turn this leads to the following problem: "How can rules that ought to be followed be so grounded that they must be followed?" (150). Whatever we make of this question and the meaning of grounding, it is very different from Goodman's view, which states that rules are valid if they conform to and systematize practice.

Before I return to the role of practice envisioned in the Goodmanian equilibrium, let me stay a little with the idea of grounding. I admit to finding it difficult to understand. Gilbert speaks of the need to ground rules. Pinto doubts the possibility that a theory might ground practice and instead holds that "our judgments about arguments and inference are guided by a tradition of critical practice" (2001: 129). But what does it mean? It might mean justify, so that rules which ought to be followed must be justified-by theoretical arguments, perhaps.

But ground can also be given a more pragmatic interpretation. It may be argued that both Goodman and Dewey see rules (theory) as grounded in practice, in the sense that they begin in practice, return to practice, and are valid in so far as they serve to systematize practice. Thus, practice might be said to ground rule $\mathrm{R}$ if, as Dewey indicates, rule $\mathrm{R}$ in the long run yields the required results. If rule $\mathrm{R}$ yields unacceptable results, as Goodman says, then it is not grounded in practice, it does not conform to practice. People might conceivably disagree as to what the required, acceptable results are, and hence as to what rules are actually grounded by practice. It is not clear to me if Gilbert and Pinto have this pragmatic sense of ground in mind.

Let me return to the role of practice in Goodman's thought. Why should we regard systematization of practice as central to the justification of inferential rules? Why should we think that fit with practice confers validity to rules and, by extension, to theory? The answer, Siegel argues, is that we should not think so. In sum, he says, "practice affords no justification to principles which fit it. The reason it does not is simple: inferential practice itself stands in need of justification" (1992: 36). All practice is, as a matter of principle, open to critique and challenge. Practice, 
lenge. Practice, therefore, should not be given such a status. Siegel then takes these views into a discussion of justification, and concludes in the end that justification by balance or equilibrium fails as an account of justification. For my purposes here, I should like to conclude that while the Goodmanian equilibrium brings theory and practice in line, it also makes theory completely dependent on practice, for its existence, its application and its justification. And with no distance between theory and practice, theory cannot provide new perspectives, new ways of seeing, contributions to the development of practice, or criticism of existing practice-all of which I think theory should do.

\section{Conclusion}

I have in this paper discussed the theory/practice relationship in the field of argumentation. My point of departure was the diagnosis offered by both Stephen Toulmin and Ralph Johnson of a gap between theory and practice, and the resulting need to bridge it. Next I discussed two possible ways of bridging the gap; one stemming from John Dewey, the other from Nelson Goodman.

It is important in this discussion to distinguish between theory in weak and strong senses. There is always weak theory in the form of preconceptions, prior beliefs, prejudices, etc. in practice; shaping and guiding it. The gap is between practice and theory in the strong sense; i.e., well-articulated theory dealing with some carefully delineated aspect of the world; typically the kind of theory that researchers try to develop. It is this kind of theory that Toulmin and Johnson have in mind, and that they think should be brought into line with practice. I, on the other hand, think that while theory in the weak sense may be inseparable from practice, theory in the strong sense should keep its distance from practice.

I see two major problems with the forms of theory and practice "being in line" that I have discussed here. The first is that all theory, regardless of the different functions they may perform, is depicted as entering into one kind of relationship with practice. No theory is left out of this relationship; Dewey explicitly states that ideas are worthless unless they pass into action and contribute to the development of practice. There is no theory for theory's own sake. The second problem is that theory is subordinated to practice. This problem is twofold. Firstly, theories must justify themselves in practice, they must prove their worth in practice, and they never get out of practice. 


\section{Tone Kvernbekk}

Weniger's view is a case in point. Secondly, practice itself seems to be taken for granted. It needs no justification; it just is what it is.

What is wrong with gaps? Let us take 'gap' to mean a mismatch between theory and practice. What would happen if we re-ordered theory such that it was brought into line with practice? Obviously theory would become more descriptively correct of practice. Of course I have nothing against some theory being brought into line; I just think that some theory should be left at a distance from practice or be left free of practice altogether. This depends on what function one thinks theory should have. If one thinks it should describe, illuminate or perhaps prescribe practice, in much the same way as weak theory does, then a gap is a problem. But if one thinks that theory should provide other ways of understanding practice, alternative explanations, critical views of practice etc., then it seems to me that some form of a gap is needed, in the form of independence and distance. I do realize that this is easier said than done, and that it raises the question if how "long" such a distance should or can be for the theory still to be relevant. And if one thinks, as I do, that theory also is a worthwhile academic pursuit in itself, free of all allusions to practice, then all theory should not be brought into line with practice. Some version of the "gap" is worth preserving for at least some of the strong theory in the argumentation field.

\section{References}

Bromberger, S. (1963). A theory about the theory of theory and about the theory of theories. In B. Baumrin (Ed.), Philosophy of science: The Delaware seminar, Vol. II, 79-106. New York: Interscience.

Carr, W. (1995). For education. Towards critical educational enquiry. Buckingham: Open University Press.

Dewey, J. (1929/1988). The quest for certainty. J.A. Boydston (Ed.), John Dewey. The later works, 1925-1953, vol. 4. Carbondale: Southern Illinois University Press.

Dewey, J. (1938/1991). Logic: The theory of inquiry. J.A. Boydston (Ed.), John Dewey. The later works, 1925-1953, vol. 12. Carbondale: Southern Illinois University Press.

Gilbert, M.A. (2007). Natural normativity: Argumentation theory as an engaged discipline. Informal Logic, 27(2): 149-161.

Goodman, N. (1983). Fact, fiction and forecast. Cambridge, MA: Harvard University Press.

Hanson, N.R. (1958). Patterns of discovery. Cambridge: Cam- 
bridge University Press.

Johnson, R.H. (2000). Manifest rationality. A pragmatic theory of argument. Mahwah, NJ: Lawrence Erlbaum Associates.

Johnson, R.H. (2005). Theory and practice again: Challenges from Pinto and Toulmin. In D. Hitchcock (Ed.), The uses of argument: Proceedings of a conference at McMaster University, pp. 222-231. Hamilton: Ontario Society for the Study of Argumentation.

Kvernbekk, T. (2008). Johnson, MacIntyre, and the practice of argumentation. Informal Logic, 28(3): 262-278.

Pinto, R.C. (2001). Argument, inference and dialectic. Dordrecht: Kluwer Academic Publishers.

Putnam, H. (2003). Foreword to the Fourth Edition. In N. Goodman (1983), pp. vii-xvi.

Scheffler, I. (1973). Reason and teaching. Indianapolis: Hackett Publishing Company.

Siegel, H. (1992). Justification by balance. Philosophy and Phenomenological Research, 52(1): 27-46.

Toulmin, S.E. (1958/2003). The uses of argument. Updated edition. Cambridge: Cambridge University Press.

Weniger, E. (1990). Ausgewählte Schriften. Zur geisteswissenschaftlichen Pädagogik. Weinheim: Verlag Julius Beltz.

Wertheimer, R. (1972). The significance of sense. Meaning, modality and morality. Ithaca: Cornell University Press. 